\title{
The sulfur-oxygen bond in sulfinylamines and sulfinylhydrazines: an AIM study
}

\author{
Heidi M. Muchall
}

Department of Chemistry and Biochemistry and Centre for Research in Molecular Modeling, Concordia University, Montreal, Quebec H3G 1M8, Canada

E-mail: muchall@alcor.concordia.ca

\section{Dedicated to Oswald S. Tee on the occasion of his $60^{\text {th }}$ birthday, and in recognition to his many contributions to Chemistry in Canada \\ (received 31 Aug 01; accepted 06 Nov 01; published on the web 14 Nov 01)}

\begin{abstract}
The quantum theory of "atoms in molecules" (AIM) has been employed for an investigation of the sulfur- oxygen bond in $\mathrm{CH}_{3}-\mathrm{NSO}$ and $\mathrm{CH}_{3}-\mathrm{NH}-\mathrm{NSO}$. A comparison with the $\mathrm{SO}$ bond in $\mathrm{SO}_{2}$ shows that the nature of the bonding is similar in all three compounds: the SO interaction is in between shared and closed-shell and is described best as a polar double bond. The electrostatic contribution to the bonding is largest in $\mathrm{SO}_{2}$ and smallest in $\mathrm{CH}_{3}-\mathrm{NH}-\mathrm{NSO}$. Within the AIM picture, the $\mathrm{SO}$ bond in $\mathrm{CH}_{3}-\mathrm{NSO}$ and $\mathrm{CH}_{3}-\mathrm{NH}-\mathrm{NSO}$ resembles the $\mathrm{CO}$ interaction in carbonyl compounds and is fundamentally different from the $\mathrm{PO}$ bond in the hypervalent $\mathrm{H}_{3} \mathrm{PO}$.
\end{abstract}

Keywords: Sulfinylamines, sulfinylhydrazines, sulfur-oxygen bond, quantum theory of atoms in molecules

\section{Introduction}

Our interest in weak bonding interactions that involve the $\mathrm{N}=\mathrm{SO}$ groups in Nsulfinylamines ${ }^{1}$ and $\mathrm{N}$-sulfinylhydrazines ${ }^{2}$ has led us to reinvestigate the nature of the sulfur-oxygen bond in these species. While in most papers on $\mathrm{N}=\mathrm{SO}$ compounds the $\mathrm{S}=\mathrm{O}$ description is used without comment, some authors are more specific, and labels such as "cumulated $\pi$-system" 3 for the $\mathrm{N}=\mathrm{S}=\mathrm{O}$ group have appeared. On the other hand, there are examples that employ the $\mathrm{S}^{+}-\mathrm{O}^{-}$ description. $^{4-6}$ In 1993, Cerioni et al. noted that no particular attention had been paid to the nature of the sulfur-oxygen bonding in Nsulfinylamines, addressed the issue through ${ }^{17} \mathrm{O}$ NMR studies, and concluded that the SO bond is a "four electron bond" that possesses double bond character, similar to the carbonyl $\mathrm{CO}$ bond. $^{7}$

The quantum theory of "atoms in molecules" (QT-AIM or just AIM) has been shown 
repeatedly to be of aid in the characterization of bonds through a topological analysis of the electronic charge density $\rho(r){ }^{8,9}$ In AIM, a bonding interaction between a pair of atoms is indicated by the presence of a bond critical point in $\rho(r)$, i.e., a point where the gradient vector field $\nabla \rho(r)$ is zero and $\rho(r)$ possesses one positive and two negative curvatures. A unique pair of trajectories of $\nabla \rho(r)$ is defined by the eigenvector that is associated with the positive curvature. These trajectories originate at the bond critical point and terminate at the pair of nuclei. In an equilibrium geometry this line through the charge density is called a bond path. The eigenvectors associated with the two negative curvatures define an infinite set of trajectories of $\nabla \rho(r)$ that originate at infinity and terminate at the bond critical point; they generate the interatomic surface. The space that is bounded by the interatomic surface and is traversed by those gradient paths that terminate at a specific nucleus is referred to as that atom's basin. The nature of a bonding interaction (covalent, ionic, van der Waals) can be determined through an analysis of the properties of $\rho(r)$ and its Laplacian $\nabla^{2} \rho(r)$ at the bond critical point, and through the properties of the atoms, which are obtained by integrating the charge density over the atomic basin.

In this contribution, we present an AIM analysis of the sulfur-oxygen bond in $\mathrm{CH}_{3}-\mathrm{NSO}$ and $\mathrm{CH}_{3}-\mathrm{NH}-\mathrm{NSO}$ as well as in $\mathrm{SO}_{2}$ for comparison. A full description, including analyses from natural bond orbitals (NBO), natural resonance theory (NRT), and the electron localization function (ELF), will be given elsewhere. ${ }^{10}$

\section{Results and Discussion}

The Laplacian maps for $\mathrm{SO} 2, \mathrm{CH}_{3}-\mathrm{NSO}$, and $\mathrm{CH}_{3}-\mathrm{NH}-\mathrm{NSO}$ are given in Fig. 1, Table 1 lists the bond critical point data for the sulfur-oxygen bonds. In a typical shared interaction, as found for example in $\mathrm{O}_{2}$, we expect a large value of the charge density at the bond critical point and a negative value for its Laplacian, indicating that the electronic charge is concentrated between the nuclei. From the values of $\rho(r)$ and $\nabla^{2} \rho(r)$ at the SO bond critical point (Table 1), it is obvious that the sulfur-oxygen bond in these compounds shows different characteristics. While $\rho(r c)$ is large, the Laplacian at the bond critical point is positive, indicating that charge is concentrated in the separate atomic basins rather than in the internuclear region, which is thus locally depleted of electronic charge. Such an interaction has been termed "intermediate" between a shared and a closed-shell interaction, where the latter exhibits a low value of $\rho(r c)$ in addition to a positive Laplacian. In an intermediate interaction the bond critical point is located close to the nodal surface of the Laplacian, and this can be seen in all three plots in Fig. 1. As a consequence, the bonded maximum in the valence shell charge concentration (VSCC) of sulfur lies within the atomic basin of oxygen. This in turn is an indication of the charge transfer from sulfur to oxygen in all SO bonds considered here, and the integrated net atomic charges ${ }^{11}$ of sulfur and oxygen confirm this finding (Table 1). Note, though, that the transfer of charge is not an indication of an ionic interaction, as $\rho(r)$ at the bond critical point has the value of a shared interaction, but rather reflects the polarity of the bond. On going from $\mathrm{SO}_{2}$ over $\mathrm{CH}_{3}-\mathrm{NSO}$ to $\mathrm{CH}_{3}-\mathrm{NH}-\mathrm{NSO}$, the $\mathrm{S}-\mathrm{O}$ 
distance increases and $\rho(r c)$ decreases (Table 1), which suggests a weakening of the bond, and we propose that this arises from a gradually reduced electrostatic component of the sulfuroxygen interaction. The most obvious indicators for this are again the net charges: while $q(\mathrm{O})$ is essentially constant, $q(\mathrm{~S})$ decreases (Table 1). This view is supported by an NBO analysis of the covalent and ionic contributions to the total bond order. ${ }^{10}$

The Laplacian can also be employed to develop the evolving picture of the nature of the SO bonding further. For all three compounds, the VSCC of oxygen exhibits two non-bonded maxima of similar magnitude in the OSO or NSO plane (Fig. 1). Even though the presence of such a non-bonded maximum does not imply the existence of an electron lone pair, it has been shown repeatedly (with few exceptions) that the maxima in the VSCC recover the electron pairs of the Lewis model. ${ }^{8,9}$ If we accept this mapping, then the two in-plane oxygen lone pairs in the compounds studied imply some degree of doubly bonded oxygen, and support for this is given by the ellipticity ${ }^{12} \varepsilon$ (a quantitative measure of the $\pi$-character of the bond) at the SO bond critical point, which is significantly different from the zero value that it would possess in a cylindrical (i.e., a single or a triple) bond.

a)
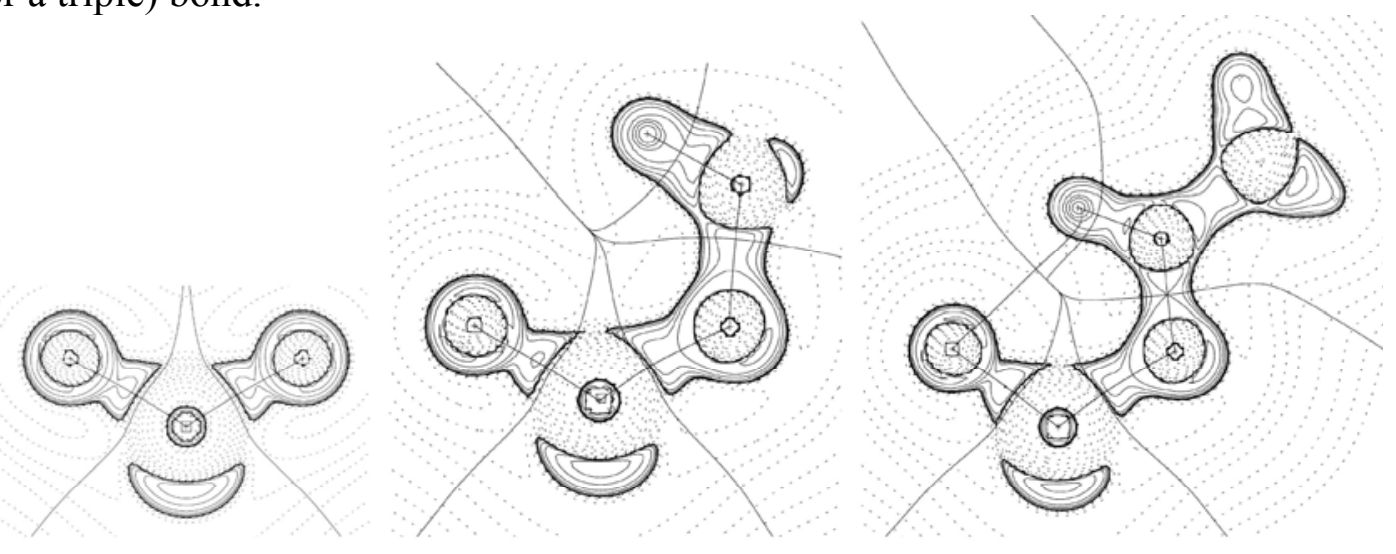

b)
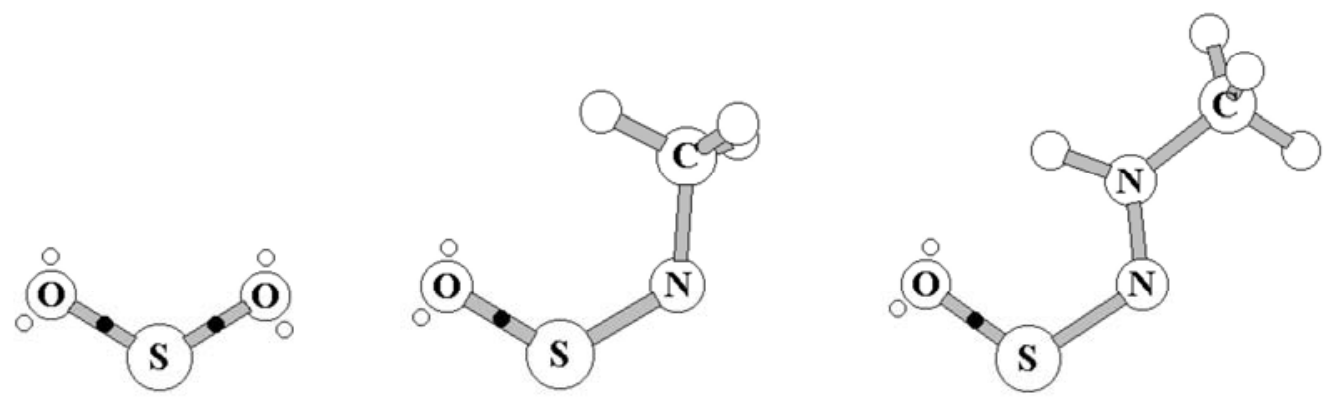

Figure 1. (a) Contour maps of the negative of the Laplacian of $\rho(r)$ for (from left to right) $\mathrm{SO}_{2}$, $\mathrm{CH}_{3}-\mathrm{NSO}$, and $\mathrm{CH}_{3}-\mathrm{NH}-\mathrm{NSO}$. The solid contour lines depict regions of local charge concentration (negative values of $\nabla^{2} \rho(r)$ ), the dashed lines regions of local charge depletion (positive values of $\nabla^{2} \rho(r)$ ). The bond paths in the plane of the map and the intersections of the interatomic surfaces with the plane are also shown. b) Orientation of the molecules in the maps of $\nabla^{2} \rho(r)$ and positions of the bonded $(\bullet)$ and non-bonded (o) maxima in the VSCC of oxygen. 
Table $1 \mathrm{~S}-\mathrm{O}$ distance, bond critical point data for the sulfur-oxygen bond, and integrated net atomic charges for sulfur and oxygen

\begin{tabular}{ccccccc}
\hline Compound & $\begin{array}{c}\mathrm{r}(\mathrm{S}-\mathrm{O}) \\
(\mathrm{pm})\end{array}$ & $\begin{array}{c}\rho\left(r_{\mathrm{c}}\right) \\
(\mathrm{e} / \AA 3)\end{array}$ & $\begin{array}{c}\nabla^{2} \rho\left(r_{\mathrm{c}}\right) \\
(\mathrm{e} / \AA 5)\end{array}$ & $\varepsilon$ & $q(\mathrm{~S})$ & $q(\mathrm{O})$ \\
\hline $\mathrm{SO}_{2}$ & 146.5 & 1.852 & 29.04 & 0.15 & 2.293 & -1.146 \\
$\mathrm{CH}_{3}-\mathrm{NSO}$ & 149.1 & 1.772 & 22.21 & 0.11 & 2.008 & -1.187 \\
$\mathrm{CH}_{3}-\mathrm{NH}-\mathrm{NSO}$ & 151.9 & 1.700 & 15.82 & 0.13 & 1.649 & -1.204 \\
\hline
\end{tabular}

The bonding situation of the $\mathrm{SO}$ bond as described above is fundamentally different from that of the PO bond in hypervalent systems, e.g. in $\mathrm{H}_{3} \mathrm{PO}$. An analysis of $\nabla^{2} \rho(r)$ revealed three nonbonded maxima in the VSCC of oxygen and a zero ellipticity of the PO bond, both of which are in accord with the $\mathrm{P}^{+}-\mathrm{O}^{-}$description for the PO bond. ${ }^{13}$ In summary, the picture that emerges for the sulfur-oxygen bond in the compounds studied here, then, is that of a polar covalent double bond, not at all unlike the carbon-oxygen bond in carbonyl compounds. ${ }^{8}$ This is nicely in accord with the experimental findings and conclusions from the ${ }^{17} \mathrm{O}$ NMR studies by Cerioni et al. ${ }^{7}$ and justifies the cumulene description of the NSO moiety. ${ }^{3}$

\section{Computational Methods}

Geometry optimizations were carried out with Gaussian $98 .{ }^{14}$ The geometries were fully optimized, without symmetry restrictions, using the B3LYP ${ }^{15}$ method and the $6-31+\mathrm{G}(\mathrm{d})$ basis set, and the wavefunctions were obtained at this level of theory. All species are energy minima. $\mathrm{CH}_{3}-\mathrm{NH}-\mathrm{NSO}$ loses the weak O...H interaction (which is illustrated in Fig. 1a by a bond path between $\mathrm{O}$ and $\mathrm{H}$ atoms) with the cc-PVTZ ${ }^{16}$ basis set, yet this does not affect the overall interpretation given here. The topological studies of the electronic charge density ${ }^{8} \rho$ were carried out with the AIMPAC ${ }^{17}$ series of programs.

\section{Acknowledgements}

Calculations were performed at the Centre for Research in Molecular Modeling (CERMM), which was established with the financial support of the Concordia University Faculty of Arts and Science, the Ministère de l'Éducation du Québec (MEQ) and the Canada Foundation for Innovation (CFI). We also acknowledge a grant of CPU time on a CRAY T90 from the Neumann Institute for Computing at the Research Center Jülich. This work was supported by research grants from the Natural Science and Engineering Research Council (NSERC) of Canada and the Fonds pour la Formation de Chercheurs et l'Aide à la Recherche (FCAR). 


\section{References and Notes}

1. Muchall, H. M. J. Phys. Chem. A 2001, 105, 632.

2. Muchall, H. M.; Marion, D., submitted to Angew. Chem. Int. Ed.

3. Kroner, J.; Strack, W.; Holsboer, F. Z. Naturforsch. B 1973, 28, 188.

4. Bak, B.; Svanholt, H.; Larsen, C. J. Mol. Struct. 1977, 36, 55.

5. Butler, R. N.; Duffy, J. P.; McArdle, P.; Cunningham, D.; O'Halloran, G. A. J. Chem. Soc., Chem. Commun. 1989, 1210.

6. Park, Y. S.; Wang, K. K.; Yong, B. K.; Ikchoon, L. J. Org. Chem. 2000, 65, 3997.

7. Cerioni, G.; Culeddu, N.; Plumitallo, A. Tetrahedron 1993, 49, 2957.

8. Bader, R. F. W. Atoms in Molecules. A Quantum Theory. Clarendon Press, 1994.

9. Popelier, P. Atoms in Molecules. An Introduction. Prentice Hall, 2000.

10. Muchall, H. M., to be submitted to J. Phys. Chem. A.

11. The net charge on an atom is calculated by integrating the charge density over the atomic basin and subtracting the nuclear charge from this number.

12. Along a bond path, the charge density is a minimum at a bond critical point and the corresponding curvature is positive; the remaining curvatures are negative. With $\lambda_{1}$ being the negative curvature of larger magnitude, the ellipticity eat the bond critical point is determined as $\varepsilon=\lambda_{1} / \lambda_{2}-1 .{ }^{8}$

13. Dobado, J. A.; Martinez-Garcia, H.; Molina, J. M.; Sundberg, M. R. J. Am. Chem. Soc. 1998, 120, 8461.

14. Frisch, M. J.; Trucks, G. W.; Schlegel, H. B.; Scuseria, G. E.; Robb, M. A.; Cheeseman, J. R.; Zakrzewski, V. G.; Montgomery, J. A., Jr.; Stratmann, R. E.; Burant, J. C.; Dapprich, S.; Millam, J. M.; Daniels, A. D.; Kudin, K. N.; Strain, M. C.; Farkas, O.; Tomasi, J.; Barone, V.; Cossi, M.; Cammi, R.; Mennucci, B.; Pomelli, C.; Adamo, C.; Clifford, S.; Ochterski, J.; Petersson, G. A.; Ayala, P. Y.; Cui, Q.; Morokuma, K.; Malick, D. K.; Rabuck, A. D.; Raghavachari, K.; Foresman, J. B.; Cioslowski, J.; Ortiz, J. V.; Baboul, A. G.; Stefanov, B. B.; Liu, G.; Liashenko, A.; Piskorz, P.; Komaromi, I.; Gomperts, R.; Martin, R. L.; Fox, D. J.; Keith, T.; Al-Laham, M. A.; Peng, C. Y.; Nanayakkara, A.; Gonzalez, C.; Challacombe, M.; Gill, P. M. W.; Johnson, B.; Chen, W.; Wong, M. W.; Andres, J. L.; Gonzalez, C.; Head-Gordon, M.; Replogle, E. S.; Pople, J. A. Gaussian 98, Revision A.7; Gaussian, Inc.; Pittsburgh, PA, 1998.

15. (a) Becke, A. D. J. Chem. Phys. 1993, 98, 5648. (b) Lee, C.; Yang, W.; Parr, R. G. Phys. Rev. B: Condens. Matter 1988, 37, 785.

16. Woon, D. E.; Dunning, T. H., Jr. J. Chem. Phys. 1993, 98, 1358.

17. Available from Professor R. F. W. Bader, McMaster University, Hamilton, ON L8S 4M1, Canada, and from the AIMPAC website (www.chemistry.mcmaster.ca/aimpac). 